\title{
Humanistic foundations of the teacher's professional activity in modern sociocultural conditions
}

\author{
Irina Khlyzova ${ }^{1,{ }^{*}}$, Lyudmila Illarionova $^{1}$ and Marina Ivanova $^{1}$ \\ ${ }^{1}$ Moscow Region State University, 105005, Radio str, 10A, Moscow, Russia
}

\begin{abstract}
The study examines the problem associated with the fact that features of dehumanization are largely manifested in modern society and in education. There is a loss of spiritual and moral values, a rejection of a worldview based on justice, a lack of attention and respect for a person is increasingly manifested, and his life and morality are being devalued. The leading role in forming the moral image of the younger generation should belong to the general educational organization, teachers and educators. In accordance with this, the goal of the study was set: to identify the level of humanization of pedagogical activity in modern sociocultural conditions. To achieve this goal, the following tasks were set and solved: on the basis of a comparative historical and pedagogical analysis of scientific literature, trace the genesis of the concept of "humanism"; characterize the humanistic foundations of modern education; consider conceptual approaches to the humanization of education; determine the pedagogical conditions for the practical implementation of the humanistic paradigm in the professional activities of university teachers, school teachers and educators. Based on the results of a survey of junior students and their inclusion in project activities to study the heritage of humanist teachers of the XIX-XX centuries, conclusions are drawn that the values of their future professional activities can be formed in the course of studying pedagogy. When carrying out educational projects that have a humanistic orientation, future teachers develop a humanistic consciousness, reorient from material values to spiritual ones, and the personality of the future teacher is humanized.
\end{abstract}

\section{Introduction}

The humanization of education is an essential characteristic of the entire education system. Humanization is a key element of the new pedagogical process, in which both teachers and pupils act as subjects for the development of their creative personality. The main meaning of the pedagogical process is the development of personality, the measure of which is an indicator of the work of educational organizations. The professional activity of a teacher always contains a humanistic, universal human principle, which he consciously brings to the fore.

*Corresponding author: hlizova_iv@mail.ru 
Even in ancient times, a model of humanistic education began to form, the essence of which was a humane approach to each person, special attention was paid to his adaptation, personality formation and preparation for life. The humanistic model was based on the student's creativity, its development as self-development, self-realization. An important principle of humanistic education was the equality between a child and an adult in the knowledge of the world without restrictions.

Ancient philosophers adhered to humanistic foundations in pedagogical activity expressed in the desire to see a person in a human, who has his own interests, lifestyle, environment and self-esteem.

So, Socrates taught his students the ability to conduct polemic, dialogue, and think logically [13]. The idea of Plato was that the cognitive process should be fascinating, and cognition should bring joy. Aristotle focused on the general culture of man. He presented education as a means of strengthening the state.

In the Renaissance, T. Campanella and M. Montaigne defined the idea of humanism in the aspect of the comprehensive development of the personality, in the combination of upbringing, productive labor and children's education.

It is widely known that Ya.A. Comensky, who developed the theoretical foundations of pedagogy, changed the vector of education with a focus on humanism, urging to teach everyone and everything.

In his theory of free natural education, J.-J. Rousseau put forward the idea of giving pupils complete freedom and adapting to their interests and propensities. He argued that improving students is a natural factor in which education should not be an obstacle to the development of this improvement.

The idea pedagogical views of J.H. Pestalozzi are dominated by the that the goal of successful education should be the harmonious development of the abilities and strength of the child, as well as the development of his human qualities.

K.N. Wentzel, L.N. Tolstoy, V.A. Sukhomlinsky announced the idea of a teacher's knowledge of spiritual life and the developmental characteristics of each pupil, as well as the teacher's creative attitude to professional activities.

All these ideas undoubtedly left their mark in the development of the humanistic foundations of modern education $[6,7]$.

It should be noted that the existing approaches to the humanization of education are determined by its orientation on spiritual and moral values. The humanistic consciousness, which is formed on the basis of the assimilation, development and appropriation of the basic values of world and national culture, directs educators to master the democratic style of communication for organizing the education and training of children at a dialogue level, to translate the democratic standards of organization and self-organization of students, pupils into the educational process and in their daily activities.

The ongoing process of humanizing the life of our society affirms the status of personality theory as a conceptual basis for the humanization of upbringing and education in general. Appeal to the individual is one of the most significant trends in the development of modern humanistic human knowledge. This is evidenced by the main provisions of the Youth Education Concept in Russia, the basis of which is the principles of humanitarization, humanization and democratization of the processes of upbringing and education. These principles are of paramount importance in solving the problems of education and socialization of youth in the digitalization of the economic and social spheres.

In this context, the development and implementation of the key ideas and provisions of humanistic pedagogy into the theory and practice of modern upbringing and education are particularly relevant. The humanistic direction in pedagogy, as a reflection of the ideas of humanistic psychology, is similar in pedagogical ideas to pedocentrism and progressionism. 
The focus of the humanistic education paradigm is a holistic personality who seeks to maximize the realization of his abilities.

In a general sense, "humanism is a worldview, the basic principles of which are: love for people, respect for human dignity, concern for the welfare of people" [10], the development and realization of one's abilities, which considers a person's walfare as a criterion for evaluating social institutions, and the principles of equality, justice, humanity as the desired norm of relations among people.

Humanism, as a rule, acts as a worldview, the basic principles of which are love for people, respect for human dignity, concern for the welfare of people. In the most general sense, humanism is seen as an orientation on the person himself and on his needs.

As a theoretical concept, humanism recognizes the human right to freedom, happiness, unhindered development and manifestation of one's abilities, creative potential. These features act in any humanistic concept as the main criteria for evaluating the activities of social institutions, targeted social attitudes and the direction of social development. In relations between members of society, humanism recognizes as a norm the principles of equal opportunities, social justice, the manifestation of a high culture of communication and humanity.

In the current conditions, the ideals of the content of humanism are subject to change, filled with a new meaning that enriched their essence. Humanism involves the rejection of the idea of violence, domination, suppression of not only man, but also nature by man. Humanism regards freedom as an attitude in which partners accept each other and recognize the values of mutual influences and interchanges. The core of the humanistic worldview and its system-forming factor is man, his acceptance as a given. This is manifested in the diversity of relations to a person, his spiritual values, to activity and, accordingly, to the world as a whole. In all this, the humanity of the individual is manifested.

The concept of humanity is defined in philosophy as "human attitude, respect for people and human dignity, love of mankind" [12]. Humanity is a personal quality, the content of which is determined by following the principles of humanism. Humanity is a combination of moral and psychological properties of a person expressing a conscious and empathic attitude to a human as to the highest value.

\section{Materials and methods}

To determine the humanistic position of the future teacher, theoretical (analysis, comparison, inductive method, synthesis, modeling) and practical research methods (observation, survey, design method, practical task), methods of mathematical statistics were used.

In accordance with the conditions for the provision of pedagogical support and the factors determining the development of the humanistic position of the future teacher, the following stages of pedagogical support were identified:

- diagnostic - recording the fact and signal of a problem, creating conditions for diagnosing a problem, establishing contact with the conditions for providing pedagogical support;

- search - organization (together with the subject of education) of the search for the causes of the problem, its reflection;

- designing the actions of the subject of education;

- activity:

a) the action is provided to the subject of education itself: the teacher approves his actions, stimulates, encourages the initiative; 
b) the teacher himself acts: direct support and assistance to the subject of education, putting oneself in the place of the subject of education.

- reflexive - a joint discussion with the subject of education of the results, successes or failures of the previous stages of activity, a statement of the fact that the problem is solvable, comprehension by the subject of education of a new life experience.

In order to study the level of patriotism among 2nd year students in the framework of teaching the discipline "Pedagogy" on the site of the Moscow Region State Pedagogical University, a survey was conducted with future teachers studying in the speciality 44.03.05. "Pedagogical education", profiles: "Russian language and literature", "Russian language and foreign English language", "Russian language and world art culture".

The questionnaire consisted of several questions:

1. What values do you consider the most important?

2. What professionally important qualities should a teacher have?

3. What is more important for you, spiritual or material values?

4. What is lasting value for you?

5. What does life success mean for you? What do you want to get in life?

6. Do you have a life purpose? Name it.

7. What qualities do you value first of all in people?

Second year students in the amount of 175 people were interviewed.

To determine the degree of appropriation of humanistic values, first and second year students were involved in project activities during the study of pedagogy. The topics and content of the projects were related to the study of the views of humanist teachers of the XIX and XX centuries. In the process of preparing and defending projects, future teachers updated their knowledge and skills, compared the activities of scientists with modern times. Great importance was attached to the education of the value aspect of future pedagogical activity. Studying the life and professional activities of humanist teachers of the XIX and XX centuries, future teachers concluded that basic human values are enduring.

So, several projects were devoted to the study of the activities of academician of the Russian Academy of Education Sh.A. Amonashvili, who is one of the most famous associates of the ideas of humane pedagogy in Russia in the late XX century. Sh.A. Amonashvili believes that the basis of humane-personal pedagogy is the humane thinking of a teacher $[1 ; 2]$. According to the design results, students came to the conclusion that when implementing modern processes of education and training, it is necessary to take into account the provisions of humanistic pedagogy of Sh.A. Amonashvili:

1. Humanistic thinking finds its roots in pedagogical, religious and philosophical teachings, it is based on the traditions of the public school.

2. Humane-personal pedagogy takes as a basis the postulate that the child is the main phenomenon in life, he is the bearer of his own life mission.

3. The process of education is carried out through the development of spiritual and moral potentials, which reveal noble features in a child.

4. Pedagogy includes social trends and cultural thinking.

5. The educational process should be based on natural principles and understanding of the personality of a person.

\section{Results}

As a result of the survey, the following results were obtained.

Most students answered to the first question that the most important values for them are money and material wealth (see Figure 1). Of course, for some students, the main values were such values as education $(5 \%)$, freedom $(7 \%)$, love $(5 \%)$, and humanism $(2 \%)$. 


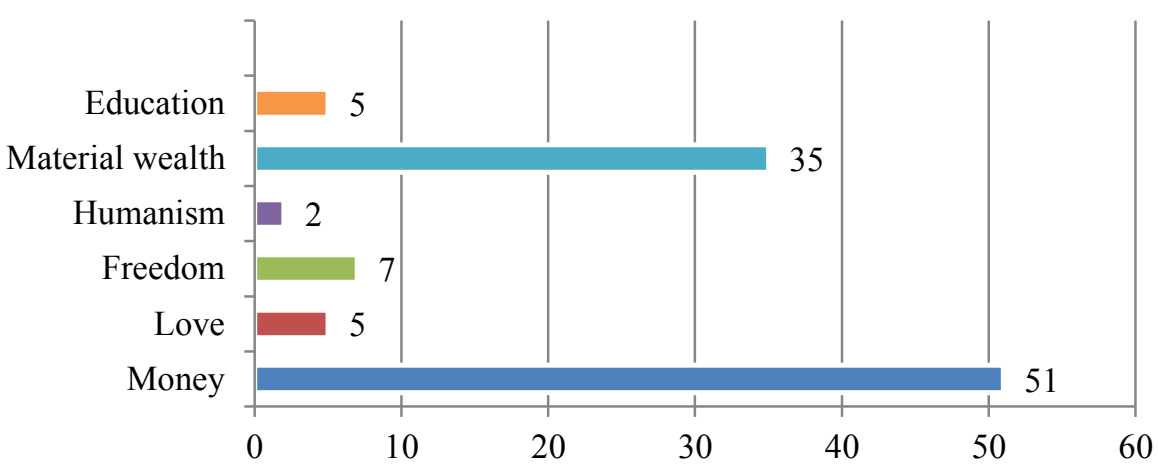

Fig. 1. The survey results before the experiment.

Based on the survey data, we can conclude that the relevance of this problem exists quite acutely, and it is necessary to strengthen attention to the education of a humane attitude to pedagogical activity. Modern society as a whole is characterized by such phenomena as moral impoverishment, a decrease in moral requirements for people, an orientation toward material well-being, cruelty, pessimism, and delinquency, which is why there are acute questions of the humanistic education of the present and future generations, in particular, future teachers.

To determine the value determinants of future teachers as the basis for the formation of their professional competence, a survey was conducted before and after carrying out project activities to study the life of humanist educators of the XIX and XX centuries to examine the hierarchy of values of future teachers. Based on the analysis of the survey conducted with future teachers of the 1 st and 2 nd year in the specialty 44.03.05. "Pedagogical education", profiles "Russian language and literature", "Russian language and foreign English language", "Russian language and world art culture", before conducting project activities to study aspects of the professional activities of humanist educators of the XIX and XX centuries, value determinants were material wealth.

After carrying out the project activity, according to the results of the survey, such value determinants as humanism, love for the child, education, and freedom began to prevail (Figure 2).

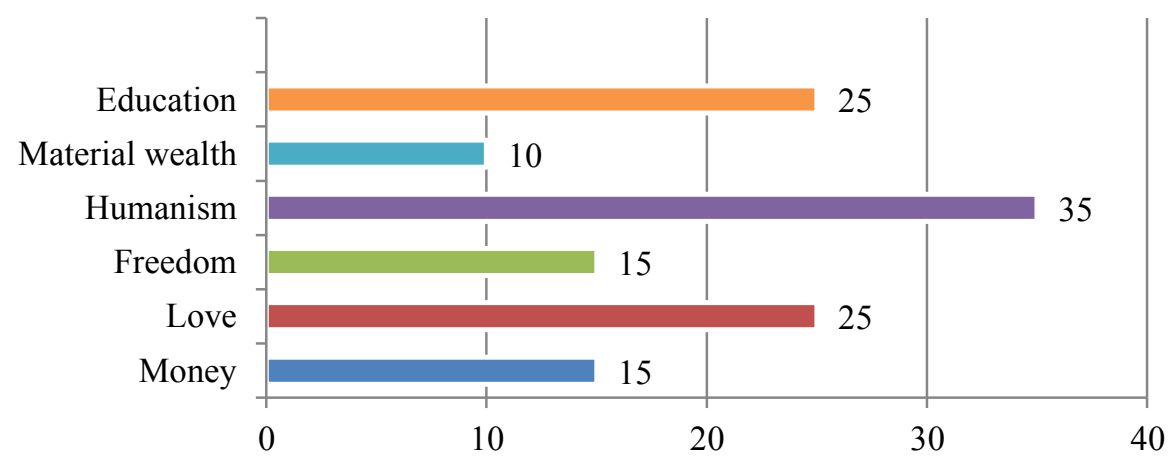

Fig. 2. The survey results after the experiment.

\section{Discussion}

In the modern humanistic model of education, the pupil and the teacher collaborate with each other, jointly determine the goals of the activity, its forms, content and evaluation criteria. There are various areas of the humanistic approach, but they are all united by their 
attitude to the stages of human development, as to unique periods of his life. Humanization is primarily a humanistic principle, which finds expression in the love of man. Human freedom is the leading principle of upbringing in humane education. Humanization excludes coercion and upholds the idea of personality development as central one. The leading tasks of humane education are:

- helping the individual to be realized in various spheres of life, the development of his creative potential;

- education of the spiritual morality of man;

- social protection, protection of life, health, human rights, environment;

- creating comfortable conditions for the development of personality.

V.V. Serikov believes that "education is a central concept not only of pedagogy, but of the whole human being" [11]. In his opinion, the creation of a modern theory and practice of education is possible only through the consistent implementation of a personality developing paradigm, where education is seen as the creation of a system of conditions for the development of the personal sphere of pupils as a structure of vital and moral meanings and value orientations.

The essence of education is revealed through the etymology of this word: "educate" means "cultivate, support what is already inherent in the nature of human existence" [3]. The author claims that the essence of modern education lies in a humanistic approach, where it is important to see an independent person in another human, to feel his view of the world, to realize that a person is unique. One of the main issues of education is understanding the personality of the child, the ability to help his formation and development, respect, because this means recognizing the value of another person, faith in his ability, providing free choice. Respect for a person implies exactingness, but these requirements should be feasible and understandable for him. The principle of unity and exactingness implies that the teacher must believe in the strength of the subject of education. Only in this case the teacher will gain favor and trust from him. To create such a position, it is necessary to single out only the positive qualities of the subject of education, to show optimism, which will follow the teacher in response.

Teachers always face a problem that requires answers to questions: how open are the boundaries of the permissibility of an invasion of the person's inner world, his free development and measures of pedagogical management. Solutions to these problems arise in connection with the orientation of researchers on a personal approach to education, the main idea of which is determined by the support on understanding personal development as the development of subjectivity, individuality of a person, and subjectivity as a property of a holistic personality.

The absolute value in education is the pupil. The humanistic approach in education is based on the equal interaction of the subjects of the educational process. This approach is based on the recognition of the value and individuality of each human as a person, the recognition of his rights to happiness, freedom and equality.

Humanization within the framework of the humanistic approach involves a transition to a system of cooperation, updating the content, forms, methods of education, to the formation of new personal qualities of those being educated. The humanization of education excludes an impersonal approach to a person. It is oriented towards humanism as a value, norm and principle of pedagogical activity [4].

Thus, the following features are characteristic of the humanization of education: the teacher's participation in the formation of certain views of the world, people and themselves, and the recognition that each human is a person who needs a special approach. The humanization of education is a value orientation, the basis of which is the restructuring of the teacher's personal attitudes. 
In the course of the study, we found that the conditions for providing pedagogical support to the subject of education can be the following:

- the desire of the subject of education to receive support and help;

- reliance on the individual capabilities of the person;

- focus on the ability of the subject of education to cope with difficulties independently;

- cooperation;

- confidentiality;

- goodwill;

- protection of human dignity, health, safety.

In accordance with the conditions for the provision of pedagogical support, the following factors were defined that determine the development of the humanistic position of the future teacher:

1. Subjective factors associated with the self-awareness of the future teacher, his acceptance of humanistic values, competence, creativity, the development of reflective and projective abilities.

This group of factors can be positioned through the following features:

- acceptance of oneself as a subject of education;

- positive attitude towards oneself;

- attitude to another as to self-worth;

- confidence in the capabilities, strengths and abilities of each subject of education;

- setting behavior on personal development;

- refusal to meet other people's expectations;

- readiness for open communication, mindset for a dialogue;

- the ability to openly and honestly express their emotions and feelings, the ability to interact;

- pedagogical tact;

- positive focus on pedagogical activity.

2. Objective factors associated with the requirements of professional activity in the humanistic paradigm. They are the basis of professional and personal self-determination and development of the future teacher, who:

- is focused on the development of the pupil, creates favorable conditions for his selfrealization;

- helps in personal development;

- owns knowledge of working with behavior individually or with a group, acts as a source of experience to which you can turn for help;

- provides cooperation in decision-making between participants in the educational process, knows how to negotiate with other people, creates a trusting atmosphere between participants in the interaction;

- knows himself well, owns self-analysis of his own actions and activities, is able to be responsible, teaches independence.

3. Objective and subjective factors associated with the organization of the professional environment, the professionalism of future teachers, i.e.:

- the presence of a reflective and innovative environment in the educational system;

- joint design of the educational process;

- confidential, open atmosphere of an educational institution;

- cooperation of subjects of the education system, co-creation, "living in a humanistic paradigm";

- objectification of personal values and meanings, the availability of information about difficulties, development and condition of members of the educational process,

- psychologization of the educational process; 
- management according to the "horizontal principle", inclusion in the analysis of the activities of public examination as a means of support, the openness of the educational system.

The teacher is a mediator between the subject of education and spiritual values. And these values should be transferred to him through the personality traits of the teacher and his estimates. A humane teacher appears before the subject of education as a model of humanity, contributes to the development of moral values of society.

What requirements must be observed in order for the pedagogical process to acquire a humane orientation? The pedagogical process should be accompanied by a feeling of free choice. This means that the subject of education has the opportunity to choose an activity, to join it and freely leave it.

It is necessary to make personally significant what is necessary for assimilation in the pedagogical process, i.e. to design activities so that the future teacher feels the compulsory educational task as freely chosen, which will lead to the fact that his desire to acquire knowledge will increase [14].

The university teacher needs to create an environment for the future teacher in which there will be a versatile activity, where the subject of education will be able to conduct experiments, gain knowledge, freely express thoughts, share experiences. The pedagogical process should encourage independent educational and extracurricular activities, encourage subjects of education to contact with the teacher, to cooperate with him.

The pedagogical process should be characterized by a pronounced developing tendency. A necessary condition and source of development are difficulties. It is important that these difficulties do not go beyond the capabilities of the subject of education. In the pedagogical process based on humane relations, feasible difficulties have a different psychological meaning for the subject of education: a condition is created for a feeling of satisfaction, joy, and confidence.

The pedagogical process should bring the joy of life to the subject of education, the future teacher. It is necessary to take time to talk about the problems that concern future teachers, to listen to their opinions, experiences, problems. This allows creating a relaxed atmosphere, recharging with positive energy and freeing yourself from negative one, and tuning in to productive activities. The future teacher will feel the joy of life if there is a spiritual contact between the teacher and the subject of education during the lesson.

Thus, the task of a university teacher is defined in the formation of future teachers of a humane attitude and understanding of society and the world around them, assistance in the formation of personality in society, as well as the development of humanity in a future teacher.

The humanity of the future teacher involves the formation of a basic personality culture, which is the basis for the formation of his self-determination and professionalism. It includes the totality of "cultures", namely: the culture of life self-determination, moral, intellectual, political, legal, physical culture, the culture of relationships and communication.

The main feature of the process of humanization of modern education is humanism as the norms, principles and values of the activities of future teachers.

Humanization in education leads to the creation of favorable conditions for the development of the future teacher; to equality, which is based on the recognition of the fact that everyone has the right to freedom, equality and happiness. The teacher must have a positive attitude towards the educated person, accept him as he is, direct him on the right path, improve the inner qualities of the future teacher and reveal his abilities and capabilities. The humanization of future teachers is carried out through adaptive and humanistic functions. Adaptive and humanistic functions are functions that have historically entrenched in the teaching profession. On the one hand, the teacher prepares the 
subject of education for the specific needs of society. And, on the other hand, he remains a guide and keeper of culture, but at the same time he works for the future of mankind, developing a personality by synthesizing the riches of human culture.

The task of the university teacher is to ensure that the pedagogical process captivates the future teacher. In this process, the future teacher should experience feelings of continuous enrichment of knowledge, experience, satisfaction of constantly growing and dynamic needs for spiritual and cognitive development. The orientation towards the development of professionalism becomes the meaning of life for the future teacher when his life positions are taken into account, his readiness for moral formation, development, and independence is realized.

Humanization is a complex process, including various means, forms and methods for students to master skills, knowledge and mechanisms for their implementation. Numerous studies of the humanistic foundations of modern education, as well as the accumulated pedagogical experience make it possible to identify the following recommendations for the introduction of humanism in modern education $[5,8,9,14]$ :

- create a humanistic educational atmosphere, a motivational-value attitude of a teacher to ongoing educational activities;

- take into account cultural, economic, social features, the level of training of students, the composition of the population;

- ensure the consciousness of the graduate as an individual of the modern technological and social environment through the informatization of education;

- put the development of cultural components and the formation of personality maturity as a priority;

- diversify educational services;

- take into account the psychological and age characteristics of subjects of education;

- resort to the subject-subject relationship between the teacher and the pupil;

- emphasize the role of the teacher as the one who will create an enabling environment for the development of the personality of the pupils;

- differentiation of education;

- attracting each subject of education to a suitable educational activity that is gradually increasing in complexity, which allows for the progressive development of the personality;

- combination of self-education and personal education;

- organization of activities in such a way that it leads to pedagogical success;

- organization of the atmosphere of pedagogical cooperation, recognition of the personality of the subject of education as the highest value and the formation of a personally-significant idea of society in him;

- inclusion of a complex of multilevel tasks of varying complexity in the lesson, depending on the individual level of development of the subject of education;

- application of technology variability and the content of training and education, the provision of the right of choice to pupils;

- creation of a special communicative environment with a communication mode in the form of a dialogue;

- the use of ethical aspects and cultural approaches during the study of subjects;

- activation of the independence of thinking, reliance on the manifestation of the individuality of the pupils, activation of the search character of education, a confidential atmosphere in the course of pedagogical activity;

- orientation of each task to a humanistic goal, a worldview idea, the use of a variety of pedagogical elements.

Humanistic projects cultivate and integrate political, national, philosophical, global, aesthetic, moral, life-meaning, scientific, environmental, civil and other human values at the level of lifestyle and worldview. 


\section{Conclusions}

Thus, we can conclude that in the modern world, changes are becoming more dynamic, global and interconnected. Human also changes in relation to himself, society, nature. The formation of a person's business qualities often occurs to the detriment of his spiritual world. The education system has one of the most difficult tasks - to contribute to the most complete development of the humanistic qualities of youth, the disclosure of their creative potential.

The humanization of education is a universal process, which means the dominance of a person and the ways of his life activity. It is based on the personal-activity character of education. Humanistic ideas have a universal and historical character, are associated with the proclamation of humanity and the value of life.

At the same time, as noted in a number of works and as practice shows, the impact of teachers on the value orientation of pupils is not enough, it requires focused scientific and pedagogical attention. When teaching pedagogy, one should activate the humanistic principle and potential of future teachers, touch upon all the educational aspects of human life, at the same time educating students in the spirit of humanism, developing their worldview in a humanistic way, and orienting them towards universal humanistic values.

\section{References}

1. Sh.A. Amonashvili, Without a heart, what do we understand (M., Amrita, 2017)

2. Sh.A. Amonashvili, Fundamentals of humane pedagogy. Book 3. School of life (M., Svet, 2015)

3. A.E. Anikin, Russian etymological dictionary (M., Russian Language Institute named after V.V. Vinogradov RAS Institute of Philology, Siberian Branch of the Russian Academy of Sciences, 2015)

4. A.M. Bayramova, Youth and science 3, 40 (2014)

5. A.S. Berberyan, B.A. Doroshin, I.G. Doroshina, Problems of modern education. Materials of the international scientific and practical conference (Penza-YerevanPrague, LLC Sociosphere Research and Publishing Center, 2014)

6. N.A. Gorlova, Pedagogy of personality. The concept of a personal approach in preschool and primary general education (M., MGPU, 2004)

7. N.A. Gorlova, Scientific and theoretical journal of the Russian Academy of Education "Pedagogy" LLC “Pedagogy” 1(84), 35 (2020)

8. N.S. Kozlova, A.V. Nekrasova, I.L. Gorbunova, Young scientist 10, 384 (2014)

9. G.B. Kornetov, Pedagogy. Education. School: ways of teaching and educating a child: monograph (M., ASOU, 2014)

10. Yu.V. Makarova, Young scientist 21, 880 (2016)

11. V.V. Serikov, Education and Society (2017)

12. The modern philosophical dictionary (M., Academic project; Yekaterinburg: Business Book, 2015)

13. B.I. Stadnichuk, Socrates: teacher, philosopher, warrior (M., Litagent, 2015)

14. O.B. Tikhomirova, N.I. Fomina, International Research Journal Yekaterinburg POLYGRAFIST Company LLC 7(49), 61 (2016) 